\title{
Monitoring Houbara Bustard Chlamydotis undulata macqueenii distribution, populations and time of occurrence within the Abu Dhabi Emirate using a network of local
} rangers

ROBERT SHELDON and FRÉDÉRIC LAUNAY

\section{Summary}

The Houbara Bustard is a winter visitor to the United Arab Emirates. Monitoring its population over large areas is difficult, due to the low density of the species and the nature of its habitat. We examined the possibility of using a network of desert rangers in the western region of the Abu Dhabi Emirate to monitor the population, timing of occurrence and distribution of Houbara Bustards in two consecutive winters. Houbara Bustards arrived in Abu Dhabi in September and moved inland towards the south of the country. The last birds were seen in March. Numbers ranged from 56 to 112 in 1994/1995 and 117 to 235 in 1995/1996. Houbara sightings were not evenly distributed within the region, with consistently higher numbers in sand-dune areas. This habitat is not optimal for Houbaras, where, in the past, they were less often encountered. The level of disturbance associated with more favourable habitats may be one reason why the birds are moving to more remote and inaccessible places. The use of a network of local rangers proved to be invaluable for gathering information on the low density Houbara population over a large area and was a very efficient way of monitoring the status of this endangered species.

\section{Introduction}

The Houbara Bustard Chlamydotis undulata macqueenii is a winter visitor to the $\mathrm{Abu}$ Dhabi Emirate. The number of wintering birds is unknown but it is frequently reported by local people to be decreasing. Houbara Bustards are very difficult to study on their wintering ground in the Arabian Peninsula because of their extremely low density and their highly cryptic behaviour. In Saudi Arabia, Seddon and van Heezik (1996) reported that a 15,000-km transect drive in each month of low abundance would have been necessary to achieve a density estimate with a coefficient of variance of $20 \%$.

Local inhabitants believe that Houbara Bustards can occur almost anywhere within the desert areas of Abu Dhabi Emirate. Studies of winter habitat use by satellite telemetry (Osborne et al. 1997) and tracks (Launay et al. 1997) also show that the species may be found in almost any sandy or gravelly habitat in $\mathrm{Abu}$ Dhabi. Monitoring Houbara densities to assess status and population trends is 
nearly impossible using traditional methods such as transect counts, which would be too time consuming when considering the extremely low population density. Nevertheless, information on population trends is essential for wildlife management and nature conservation. Conservation management, however, does not always require extreme accuracy in the population estimate, as long as methods remain consistent over time and the area surveyed is representative for the population as a whole (Bibby et al. 1992).

A network of camps of desert rangers, whose principal task during winter is to locate Houbaras for falconers by finding tracks, is operational throughout the Emirate of Abu Dhabi. Since 1993 researchers from the National Avian Research Center (NARC) have been developing close links with a number of these camps in an attempt to monitor the population of Houbaras crossing the Emirate.

\section{Study area and methods}

The rangers' camps are distributed throughout the Emirate of Abu Dhabi but NARC researchers have been working with those of the western region (Figure 1). In the winter of 1994 / 1995 we worked with five camps and this was extended in the 1995/1996 season to seven camps. The study area is situated in the west of Abu Dhabi Emirate. In the south, sand-dunes are the characteristic feature. The sand-dunes are higher in the Wutayd region (Figure 1). Vegetation lies between the dunes, with species such as Tribulus sp. and Cyperus conglomeratus being dominant. In the north, the main habitat feature is extensive gravel plains with a high plant diversity (Oatham 1994), dominated by Haloxylon sp. and Zygophyllum sp. shrubs.

The three-toed track of the Houbara Bustard is particularly distinctive, although confusion may arise amongst less experienced fieldworkers with the presence of Stone Curlew Burhinus oedicnemus. By locating animal tracks, the rangers can identify the species, the age of the track and even certain individual animals. Track counts of birds may serve as an index of population, assuming the number of tracks correlates with the number of birds. Tracks, however, are remote from the animal in time and it is difficult to determine how many birds made the tracks.

The rangers at each camp are divided into patrol teams of two, with a four-wheel drive vehicle fitted with a VHF radio handset. Each camp is equipped with a VHF radio and employs a full-time radio operator. The radio system allows for communication between each ranger camp and patrol vehicle throughout the whole ranger network. Each day the rangers are assigned different areas to patrol by the head ranger. The camp acts as a centre with patrols radiating from it in different directions. Areas were patrolled randomly, and the rangers were not limited to existing desert tracks. Upon locating tracks or visual sightings of Houbaras, relevant information (number of tracks or birds seen, location) was relayed to the associated camp and recorded by the radio operator.

Our visits to the camps were very informal. They were visited in no particular order and no set time was allocated for visiting or for the length of stay at each camp. A survey questionnaire was developed and translated into Arabic. It requested information on the date, number and location of Houbaras. At each 


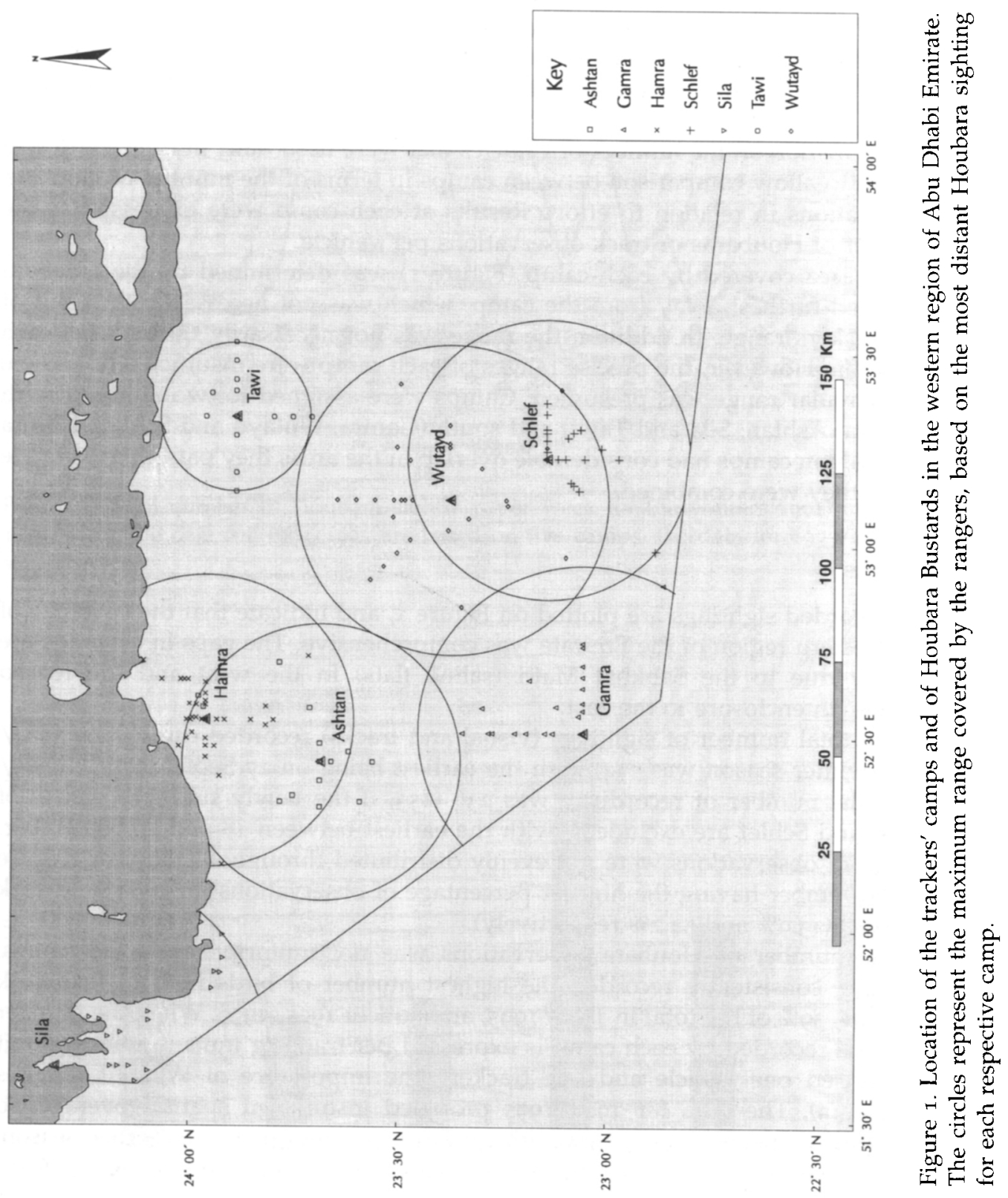


camp the form was distributed to the radio operator, who was shown exactly how to complete it so that data collection was standardized. Completed forms were collected fortnightly. To improve the accuracy of the questionnaire, the chief trackers were contacted every two weeks by mobile phone to cross-check the data collected. Upon return to NARC, the surveys were translated from Arabic to English and the information on Houbara numbers was entered on to a database. Locations of Houbara sightings were converted into estimated latitude/longitude coordinates and the resulting positions were plotted on a map.

Information on the number of vehicles that were used daily at each camp was sought to allow comparison between camps in terms of the number of Houbara observations in relation to effort. Results at each camp were expressed as the number of Houbaras or track observations per vehicle.

The area covered by each camp (Figure 1) was determined by the Houbara recorded furthest away from the camp, which was not necessarily the limit of the trackers range. In addition the range was not necessarily the same in each direction. However, the precise ranges of each camp were insufficiently known, so a circular range was presumed. Camps were assigned to two regions, north (Hamra, Ashtan, Sila and Tawi) and south (Gamra, Wutayd and Schlef). Hamra and Ashtan camps had considerable overlap in the areas they patrolled, so in the study they were combined.

\section{Results}

All recorded sightings are plotted on Figure 1, and indicate that the coverage of the western region of the Emirate was comprehensive. The gaps in coverage are mainly due to the Sabkhat Matti (saline flats) in the west and the fenced Baynunah enclosure to the east.

The total number of sightings (visual and tracks) recorded during the 1994/ 1995 winter season was 114, with the earliest being on 27 September. In 1995/ 1996 the number of recordings was 236 (153, if the newly surveyed camps of Tawi and Schlef are excluded), with the earliest between 18 and 23 September. Houbara observations were not evenly distributed throughout the year (Figure 2), November having the highest percentage of observations for both fieldwork seasons $(43.9 \%$ and $54.2 \%$ respectively).

The number of Houbara observations was not uniform across the camps. Wutayd consistently recorded the highest number of birds in both fieldwork seasons, $39 \%$ of the total in $1994 / 1995$, and $30 \%$ in $1995 / 1996$. When the number of birds recorded by each camp is expressed per tracking units (a tracking unit comprised one vehicle and one tracker), the importance of Wutayd remains (Figure 3). The data for 1994/1995 provided insufficient spatial coverage, so analysis of spatial distribution with time was limited to the $1995 / 1996$ season. There was a general pattern in spatio-temporal distribution of Houbara recordings, with a peak in observations in the north, followed by peaks in the south (Figure 4). The number of Houbara sightings differed significantly with time of the year $(F=9.745, d f=6, P<0.001)$ but not with location (north or south) $(F=0.064, d f=1$, N.S. $)$. 


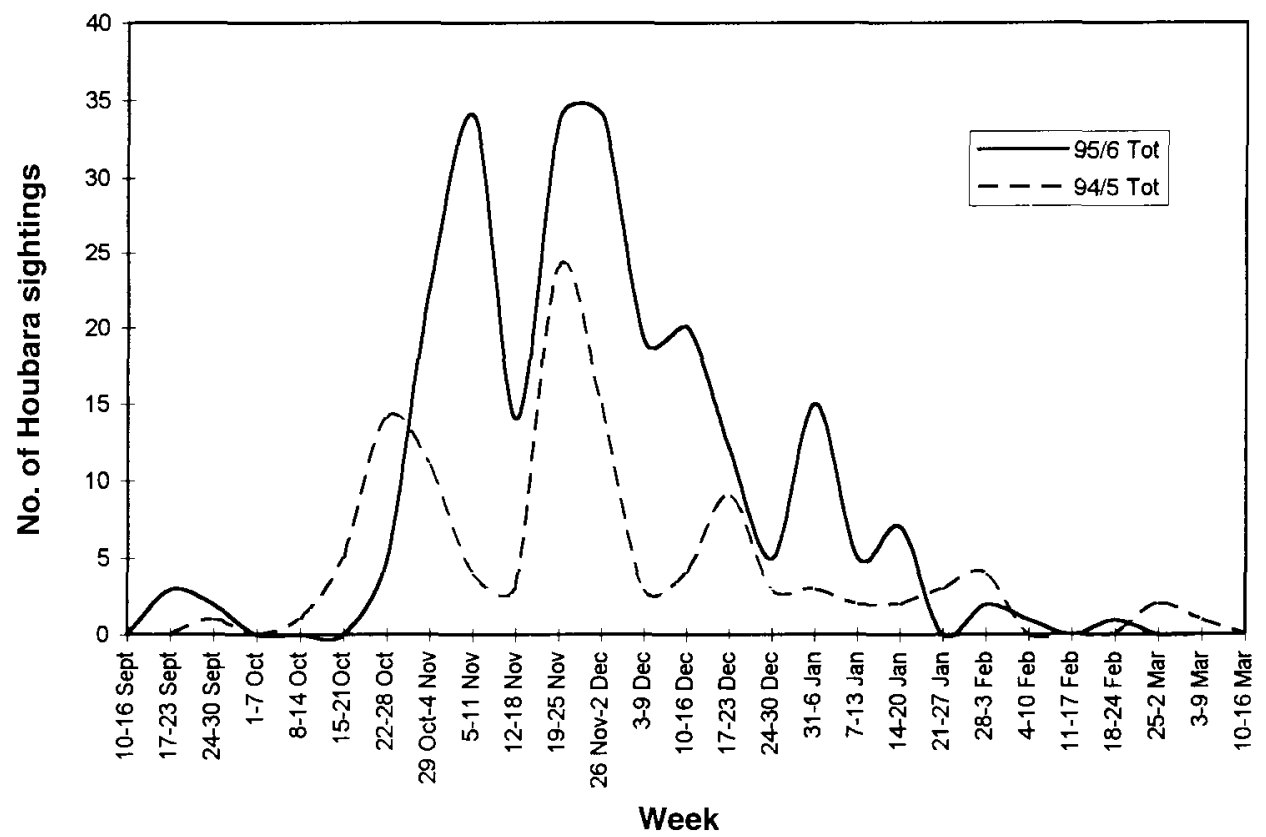

Figure 2. Total number of Houbara sightings per week for the winters 1994/1995 and 1995/1996. The data for $1994 / 1995$ are based on five camps, the data for $1995 / 1996$ on seven camps.

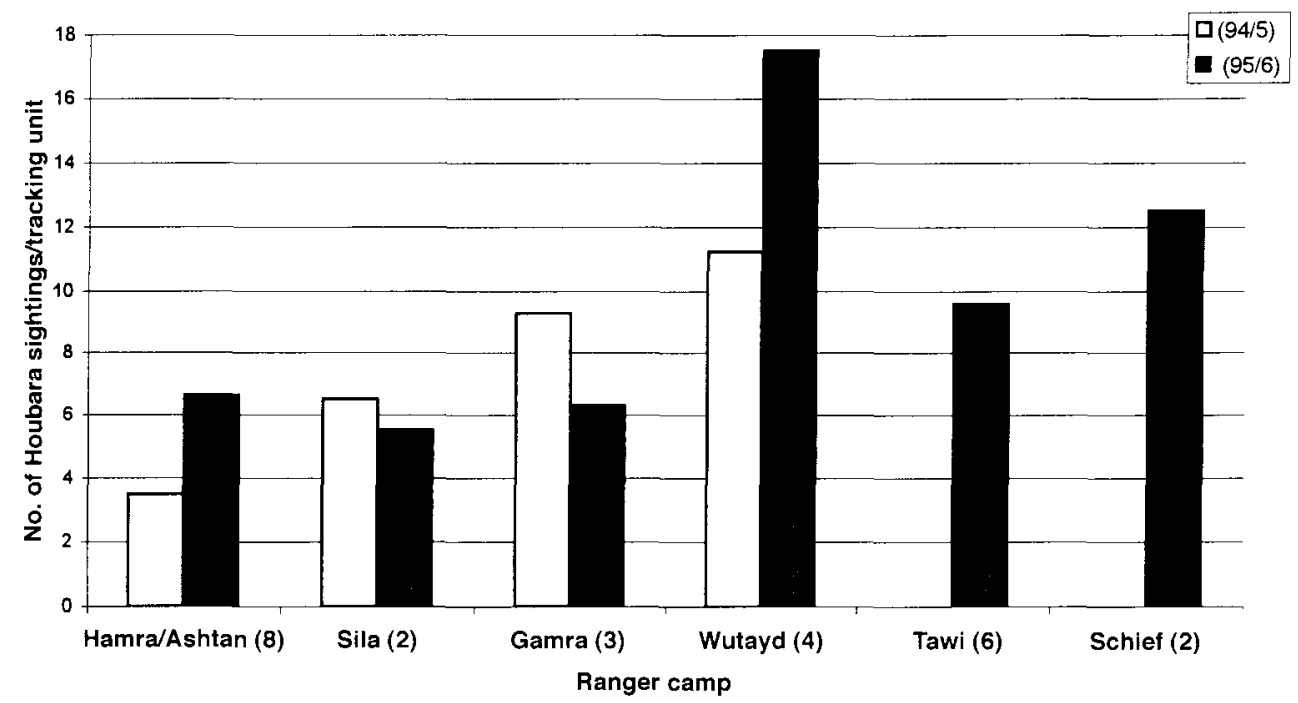

Figure 3. Number of Houbara sightings/tracking unit per camp for two consecutive winters. A tracking unit comprised one car and one tracker. 


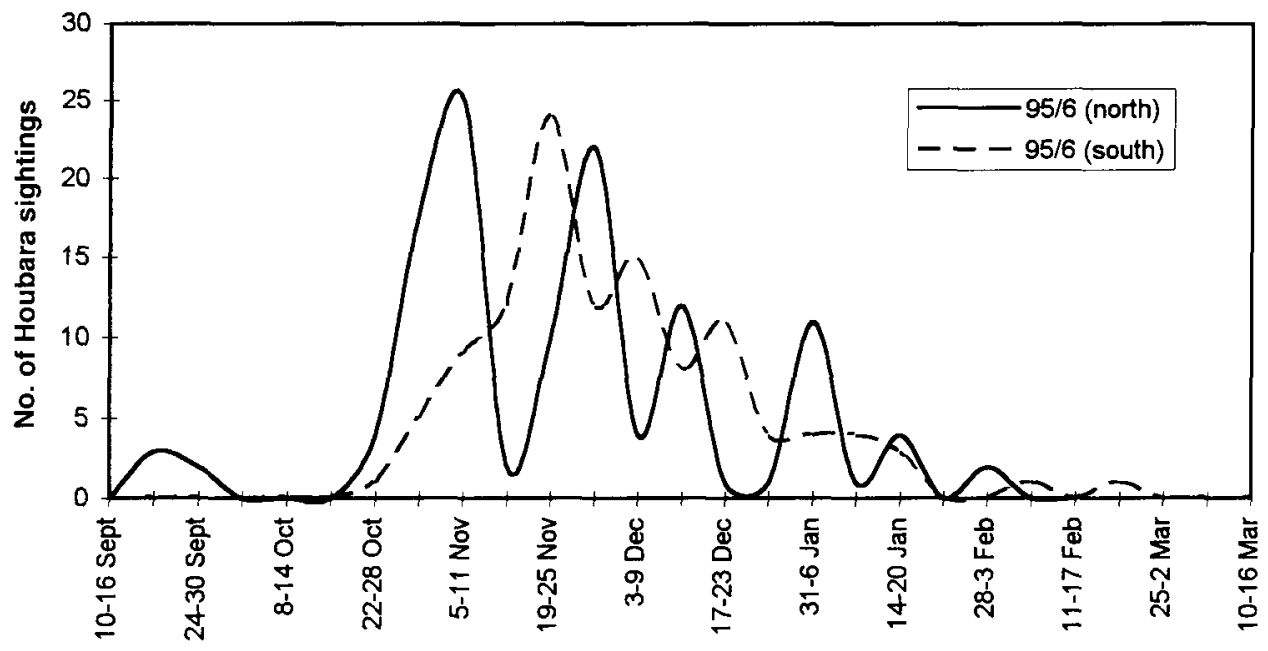

Date by (week)

Figure 4. Distribution of Houbara sightings according to the location of the camps (north: Hamra/Ashtan, Sila, Tawi; south: Gamra, Wutayd and Schlef) for the 1995/1996 winter.

Observations of single birds were most common, $73 \%$ in $1994 / 1995$ and $69 \%$ in 1995/1996, and occurrences of groups of more than three birds were rare ( $3.84 \%$ and $1.75 \%$ of the total observations each season). The largest flock size recorded was five (Table 1 ).

In the northern camps more Houbara were recorded by location of tracks, and in the southern camps visual sightings were more common (Table $2, \chi^{2}=36.67$, $d f=1, P<0.001)$.

\section{Discussion}

Studying Houbara Bustards is difficult due to the secretive nature of the birds and their habitat preferences. Survey drive techniques are usually used to

Table 1. Houbara Bustard group sizes in two consecutive winters in the western region of Abu Dhabi Emirate

\begin{tabular}{|c|c|c|c|c|c|c|c|c|}
\hline Group size & Sept. & Oct. & Nov. & Dec. & Jan. & Feb. & Mar. & Total \\
\hline \multicolumn{9}{|c|}{ 1994/1995 (five camps) } \\
\hline 1 & $\mathbf{1}$ & 11 & 21 & 13 & 8 & 1 & 2 & 57 \\
\hline 2 & & 6 & 3 & 2 & & & & 11 \\
\hline 3 & & $\mathbf{I}$ & 5 & $\mathbf{I}$ & & & & 7 \\
\hline $3^{+}$ & & & 2 & & 1 & & & 3 \\
\hline \multicolumn{9}{|c|}{ 1995/1996 (seven camps) } \\
\hline 1 & 3 & 11 & 58 & 33 & 13 & $\mathbf{1}$ & & 118 \\
\hline 2 & $I$ & & 24 & 12 & 8 & & & 45 \\
\hline 3 & & & 3 & 2 & & & & 5 \\
\hline $3^{+}$ & & & 3 & & & & & 3 \\
\hline
\end{tabular}


Table 2. Number of visual or track sightings of Houbara Bustards from the different camps of the western region of Abu Dhabi Emirate. Hamra/Ashtan, Sila and Tawi are in the north, and Gamra, Wutayd and Schlef are in the south

\begin{tabular}{|c|c|c|c|c|}
\hline & \multicolumn{2}{|c|}{ I994/1995 } & \multicolumn{2}{|c|}{$1995 / 1996$} \\
\hline & Track & Visual & Track & Visual \\
\hline Hamra/Ashtan & 20 & 8 & 40 & 13 \\
\hline Sila & 12 & 1 & 3 & 8 \\
\hline Tawi & & & 31 & 27 \\
\hline Sub total & 32 & 9 & 74 & 48 \\
\hline Gamra & 15 & 13 & 9 & 10 \\
\hline Wutayd & 10 & 35 & 23 & 47 \\
\hline Schlef & & & 4 & 21 \\
\hline Sub total & 25 & 48 & 36 & $7^{8}$ \\
\hline Total & 57 & 57 & 110 & 126 \\
\hline
\end{tabular}

estimate Houbara density but they often give very low estimates (Seddon and van Heezik 1996) especially of wintering birds, while they are time and labour intensive.

The local people's knowledge of their surroundings is being used increasingly for gathering information relating to species conservation. Involving the local desert rangers in monitoring the wintering Houbara population has some clear advantages, including the coverage of a greater study area. Previous studies on Houbara Bustards in Abu Dhabi Emirate were limited in area and very labour intensive (Launay et al. 1997) or were very expensive and based on a very limited number of birds (Osborne et al. 1997).

From the data collected, the coverage of the western region appeared to be comprehensive. The only areas where the coverage was poor were the regions west of the Tawi camp, which is a large enclosed forestry plantation, and the area to the south-east of the Sila camp which is dominated by the featureless Sabkha Matti. Both these habitats are normally not used extensively by Houbara in the U.A.E. (Launay et al. 1997, Osborne et al. 1997). Differences in search methods were due to the nature of the terrain. In the north, the camps were generally in areas of flat gravel plain, or small undulating sand-dunes, where driving was easy. In these areas, the rangers usually tried to find tracks, whereas in the south in areas of very high sand-dunes, driving was difficult and the rangers concentrated their search efforts in vegetation patches between sand dunes, where they saw Houbara more often, as indicated by our results.

Our results indicate an uneven distribution of Houbara locations, with the camp of Wutayd, surrounded by an area of high sand-dunes, having most observations in both fieldwork seasons. Previous studies (Cramp and Simmons 1983, Johnsgard 1991, Launay et al. 1997, Osborne et al., 1997) suggested that the relatively well vegetated gravel plains surrounding the northern camps would be the preferred habitat of Houbara. The greater number of birds recorded in less preferred habitat may be an indication of habitat degradation in the north or, as the local Bedu suggested (Loughland 1995), the high level of disturbance (road, forestry plantation and military activities) forcing wintering Houbara to seek refuge in a suboptimal environment. 
The number of Houbara observations peaked in November in our study areas, as was also noted by Launay et al. (1997), corresponding with Mansoori's (1985) observations of arrival of wintering Houbara Bustards in the south of Iran in October and November. Some populations of the macqueenii subspecies are migratory, departing from their breeding grounds in central Asia between September and November (Launay et al., in press) and it is thought that the birds wintering in U.A.E. are coming through the Gulf. It is thus a reasonable assumption that Houbaras will be observed in the north (on the Gulf coast) first. The data obtained by the rangers in 1995/1996 confirmed this. There are three observation peaks in the northern camps with consequently corresponding, albeit smaller, peaks in the southern camps. This is consistent with the observations of Osborne et al. (1997) showing that Houbara Bustards are moving south in Abu Dhabi Emirate between October and December and moving north in January and February. It is reasonable to assume that Houbara Bustards are actually moving through U.A.E. during the winter and not actually spending the winter in Abu Dhabi Emirate. It also implies that some of the birds arriving in the north and moving south during the winter are being recorded by the rangers in the camps in both areas. This must be considered when estimating the number of birds crossing U.A.E. during the winter. The number of birds recorded could thus be as low as 56 in 1994/1995 and 112 in 1995/1996 if we assume that all the birds were seen twice and as high as 117 in 1994/1995 and 235 in 1995/1996 if birds were only seen once.

The data collected showed that the majority of birds were singles ( $73 \%$ and $69 \%$, respectively, of the observations for the two fieldwork seasons). Seddon and van Heezik (1996) found that lone birds accounted for only $33 \%$ of the observations in the Harrat al Harrah protected area in Saudi Arabia; however, the nature of the terrain there (bare volcanic plateau with narrow gullies of vegetation) may concentrate Houbaras, whereas the habitat is more homogenous in Abu Dhabi Emirate.

We conclude that the existence of the trackers network in Abu Dhabi Emirate is a very efficient and reliable way of monitoring the population of Houbara Bustards during winter. Furthermore information on timing of arrival, distribution and grouping can be gathered over a very wide area. We envisage using this network more extensively in the future to monitor a wider range of desert species.

\section{Acknowledgements}

We are grateful to H.H. Sheikh Khalifa bin Zayed Al Nahyan, Crown Prince of Abu Dhabi and President of the National Avian Research Center, and H.H. Sheikh Mohammed bin Zayed Al Nahyan, Chairman of the Board, for financing this research and to Mohammed al Bowardi for his invaluable support. The authors also would like to thank all the trackers from the western region of Abu Dhabi Emirate for their hospitality and help.

\section{References}

Bibby, C. J., Burgess, N. D. and Hill, D. A. (1992) Bird census techniques. London: Academic Press. 
Cramp, S. and Simmons, K. (eds) (1983) The birds of the Western Palearctic, 2. Oxford: Oxford University Press.

Johnsgard, P. A. (1991) Bustards, Hemipodes and Sandgrouse. Birds of dry places. Oxford: Oxford University Press.

Launay, F., Combreau, O., Aspinall, S. J. and Loughland, R. L. (in press) Migration routes and stop-overs in Central Asian Houbara Bustard. Fifth Symposium on Wildlife Telemetry. Strasbourg, France, 25-30 August, 1996.

Launay, F., Roshier, D., Loughland, R. and Aspinall, S. J. (1997) Habitat use by Houbara Bustard (Chlamydotis undulata macqueenii) in arid shrubland in the United Arab Emirates. J. Arid Environ. 35: 111-121.

Loughland, R. L. (1995) A survey of information on the natural desert habitat of Abu Dhabi Emirate, The United Arab Emirates. Abu Dhabi: National Avian Research Center (Internal Research Report 38).

Mansoori, J. (1985) The status of the Houbara Bustard in Iran. Bustard Stud., 3: 97-99.

Oatham, M. P. (1994) Description and manipulation of the Abu Dhabi rangeland vegetation for the Houbara Bustard. PhD thesis, University of Kent at Canterbury, U.K.

Osborne, P. E., Launay, F. and Gliddon, D. G. (1997) Wintering habitat use by Houbara Bustards Chlamydotis undulata in Abu Dhabi and implications for management. Biol. Conserv. 81: 51-56.

Seddon, P. J. and van Heezik, Y. (1996) Seasonal changes in Houbara Bustard Chlamydotis undulata macqueenii numbers in Harrat al Harrah, Saudi Arabia: implications for managing a remnant population. Biol. Consero. 75: 139-146.

ROBERT SHELDON and FRÉDÉRIC LAUNAY

National Avian Research Center, Environmental Research and Wildlife Development Agency, P.O. Box 45553, Abu Dhabi, United Arab Emirates. 